Roger Williams University

DOCS@RWU

$9-6-2008$

Non-profit Health Care Services Marketing: Persuasive Messages

Based on Multidimensional Concept Mapping and Direct

Magnitude Estimation

Michael L. Hall

Roger Williams University, mhall@rwu.edu

Follow this and additional works at: https://docs.rwu.edu/fcas_fp

Part of the Arts and Humanities Commons

Recommended Citation

Hall, Michael L. 2008. "Non-profit Health Care Services Marketing: Persuasive Messages Based on Multidimensional Concept Mapping and Direct Magnitude Estimation." Health Marketing Quarterly 26 (3).

This Article is brought to you for free and open access by the Arts and Sciences at DOCS@RWU. It has been accepted for inclusion in Arts \& Sciences Faculty Publications by an authorized administrator of DOCS@RWU. For more information, please contact mwu@rwu.edu. 


\title{
Non-profit Health Care Services Marketing: Persuasive Messages Based on Multidimensional Concept Mapping and Direct Magnitude Estimation
}

\author{
Michael Hall, Ph.D. \\ Roger Williams University \\ Bristol/Providence, Rhode Island
}

\begin{abstract}
Persuasive messages for marketing healthcare services in general and coordinated care in particular are more important now for providers, hospitals, and third-party payers than ever before. The combination of measurement based information with creativity may be among the most critical factors in reaching markets or expanding markets. The research presented here provides an approach to marketing coordinated care services which allows healthcare managers to plan persuasive messages given the market conditions they face. Using market respondents' thinking about product attributes combined with distance measurement between pairs of product attributes, a conceptual marketing map is presented and applied to advertising, message copy, and delivery. The data reported here are representative of the potential caregivers for which the messages are intended. Results are described with implications for application to coordinated care services. Theory building and marketing practice are discussed in the light of findings and methodology.
\end{abstract}

Keywords:

Coordinated care, concept mapping, persuasive messages, message delivery, marketing, magnitude estimation 


\section{Introductory Notes}

Michael L. Hall, Chair and Program Director

Public and Health Administration

Roger Williams University

Room 408

150 Washington Street

Providence, Rhode Island 02903-9998

mhall@rwu.edu

Dr. Hall is Chair and Program Director of Public and Health Administration at Roger Williams University. He holds a PhD and Master's Degrees from The University of Oklahoma. Dr. Hall has published in a variety of professional journals including the Journal of Nonprofit and Public Sector Marketing. He served for four years with Community Workshop, Inc. (CWI), a \$15 million human services nonprofit organization. While on staff with CWI Dr. Hall conducted market research for a new revenue generating sales operation owned by CWI and developed focus group protocols. He has also conducted strategic marketing support for CWI and the Watervliet Army Weapons Arsenal.

\section{Non-profit Health Care Services Marketing: Persuasive Messages Based on Multidimensional Concept Mapping and Direct Magnitude Estimation}

\section{Introduction:}

The planning of persuasive messages for marketing and outreach in healthcare is more critical than ever in an environment of restricted resources and managed care (Berkowitz, 1996, p. 3). The traditional approach to marketing and persuasive messages is typically through a combination of creativity, focus group research, and experience (Berkowitz, 1996, p. 149). However, concept mapping combined with direct magnitude estimation can provide a scientific and measurement based approach to messages for patients, doctors, and healthcare administrators. Theoretical and practical marketing can, as a result, take on added significance and strength. The combination of theory with practice becomes a significant tool for marketers and researchers. 


\section{Background:}

Continuity of care is essential to patients with chronic diseases, their families and the elderly (Ouwens, Wollersheim, Hermens, Hulscher, \& Grol, 2005, Stille, Jerant, Bell, Meltzer, \& Elmore, 2005). The patients and their families need coordinated care allowing them to interact with one consistent primary care provider (Rantz, Marek, \& Zwygart-Stauffacher, 2000). Chronic illness and/or conditions created by aging require that patients and their families feel comfortable with their care and that they be confident their healthcare provider has their best interests in mind during treatment (Starfield, 1998).

The Life Institute of Albany, New York, situated in the Albany Veterans Administration Hospital, began to conceive of a coordinated care service for patients suffering chronic diseases of aging, patients with terminal illnesses and family caregivers of such patients. The coordinated care service that the Institute planned was to be a new market entrant. Given that the service did not exist for the market the Institute had in mind, establishing a market presence and creating a large enough market to sustain the service was necessary. Recognizing the need to establish the service in the market quickly and not fully experienced in the development of marketing messages, the Institute's executive management decided that a sound research and measurement approach was needed. They agreed to a concept mapping market research project.

Concept mapping has advantages in marketing because of its use of focus groups, structured results in objective form, and representation of ideas expressed as a perceptual map (Bigne, et al., 2002). Bigne, et al., describe the technique as employing cluster analysis and multidimensional scaling. They say the technique identifies sets of variables that foster customer perceptions of products or services. 
Stanton and Lowenhar note the concept mapping approach allows interpretation of complex stimuli on the part of consumers (Stanton and Lowenhar, 1977). Stanton and Lowenhar demonstrate how concept mapping analysis establishes "psychological proximities" shared within a common domain.

Shewchuk and O'Connor applied concept mapping to health care marketing directed at the elderly (Shewchuk and O'Connor, 2002). They call their approach an "illustrative approach to planning and marketing". Their illustrative framework is used to provide suggestions for health care marketing and planning.

Trochim, et al., use concept mapping to derive 8 rules from their concept mapping investigation of 133 respondents as they examine ways to address challenges in and create improvements for public health (Trochim, et al., 2006). In doing so, they are following Freeman and Jessup whose research indicates the usefulness of concept mapping for ease of use, benefits to the users of the approach and, importantly, for communication (Freeman and Jessup, 2004).

The research presented here drew upon concept mapping methodology, as reported above, and that of Woelfel and Fink who have added direct magnitude estimation to product pair attributes for creating concept maps in the marketing of products such as automobiles, services, and political campaigns (Woelfel \& Fink, 1980, p. 205). The research also thematically follows the multidimensional scaling approach of Trochim et al. in health promotion or tobacco control (Trochim, Stillman, Clane, \& Schmitt, 2003).

\section{Direct Magnitude Estimation}

Direct magnitude estimation (DME) adds additional information to concept mapping methodology. DME information becomes important in the analysis of concept maps providing additional mathematically based information for the interpretation of the resulting map and the 
selection of concepts from that interpretation to be used in marketing messages. The concept mapping methodology combined with DME can assist in interpreting how important a concept or product attribute is to a potential patient, doctor, or healthcare administrator. The product attribute is placed in distance contrast to a criterion. The respondent is, therefore, asked to determine how far apart or different a product attribute is from another product attribute using the criterion. In doing so, the measurement of product attributes or concepts is following the well established measurement principle of a reference (Whitehill, Lee, \& Chun, 2002, Eadie \& Doyle, 2002).

The kind of reference used in DME based concept mapping is akin to that applied in the physical sciences such as physics. Measurements applied by physicists, for example, use the planet earth as the reference point for measuring distances between celestial bodies and other objects in space. The measurement used by physicists is relative to the Earth. Paired comparison of product attributes in concept mapping establishes a reference point in the same relative way. Moreover, as Born states, the DME approach is objective since the observation of the distance data by the researchers is independent of the researchers (Born, 1965). Objectivization is crucial since observations will vary as a result of the different arbitrary standards and comparisons of each investigator (Woelfel \& Fink, 1980, p. 22).

Woelfel and Fink (1980) also emphasize that DME based concept mapping allows for empirical verification, i.e., the data are verifiable by other researchers (p. 23). Empirical verification then allows statements about relationships among observations within a consensual, albeit arbitrary, framework. Thus, the research into coordinated care for the Life Institute reported here can be reproduced by others wishing to verify and replicate the research presented. 
DME is also important to the measurement of product attributes because there is no limit to the distance the respondent can choose between concepts. An advantage of DME, therefore, is that the scales are generally without the systematic bias that is associated with interval scales (Eadie \& Doyle, 2002). For instance, equal appearing interval (EAI) scales require that observers provide ratings based on a fixed predefined scale that implies that the perceptual distance, weight, or magnitude between numerical components is equal (Eadie \& Doyle, 2002). As a result, the amount of information generated can be no greater than the predefined limits set by the researchers. Contrastingly, DME, without such limitations, allows the respondent to choose distances without bounds. Stevens (1974) has shown that the prescribed nature of an EAI scale may not capture a respondent's full range of perception (Eadie \& Doyle, 2002). Stevens indicated that people do not perceive intervals as equal at different locations along the scale (Eadie \& Doyle, 2002). As an example, the difference respondents perceive between " 1 " and " 2 " on the scale may not be equal in magnitude to the difference perceived between " 4 " and " 5 " or between "8" and "9" (Eadie \& Doyle, 2002).

Therefore, in the crafting of persuasive messages limited measurement will constrict the data available for the creative portion required in the development of marketing messages. By combining creativity with more inclusive information, a message with greater predictable results can be generated.

\section{DME Based Concept Mapping Analysis:}

The DME Concept mapping methodology adds to the traditional focus group research and follows the patterns of open ended questioning of other marketing concept map developers. As in a focus group, researchers choose potential market respondents. Respondents are asked a series of open-ended questions intended to solicit important product attributes and/or concepts. 
The responses from the open-ended questions are then analyzed through cluster analysis software to determine frequency of responses but, more importantly, co-occurrence of responses. In doing so, this part of the analysis is applying a form of neural network analysis or pattern analysis (Song \& Zhao, 2004;Somers, 2001). That is to say, respondent's answers to the open-ended questions are counted but are also analyzed for how respondents are thinking about the concepts. The analysis is seeking to examine how respondents connect their thoughts about the product's attributes.

Once the software has analyzed the concepts in this fashion, the researchers are able to determine clusters of concepts (Woelfel, 1993). The clusters are then used to develop a series of seven to ten key product attributes or concepts. To these product attributes are added the two key concepts of the product itself or, in the case of coordinated care, the service, and the respondent/customer, referred to in DME concept mapping methodology as the self. The key concepts/attributes, along with the product or service, are arrayed in pairs one against the other. The respondent is then asked to apply the DME based measurement by indicating the distance or dissimilarity perceived between each pair after being given a related concept pair as the reference point.

\section{Methodology: The Coordinated Care Research}

Research began once permission for access to a sample of the population of potential customers at a series of locations in Albany, New York was granted. Those locations included senior centers in Albany, New York with which the Life Institute had affiliations. A set of openended questions was posed to the potential market respondents. Those questions are displayed in Exhibit 1. While the questions guided the interview, as in focus groups, the intention was to engage the respondents in a conversation. 


\section{EXHIBIT 1}

1. If you or your family member (parents, spouse) became seriously ill, for example, heart disease, Alzheimer's disease, cancer, what help or services would you imagine you might need or want for yourself or your family?

2. Imagine the serious illness is worsening and requiring additional care. What added help or services do you think would be needed as the health of your or the family member became poorer?

3. Imagine assistance is needed in understanding and managing help and services for a serious illness. What do you think you might need help in understanding or in managing those services?

4. In addition to what we have already asked, do any other ideas come to mind about serious illness in general?

Imagine your income and health insurance coverage are about the same as they are now when you or a family member became seriously ill.

5. If some of the help or services you needed were not covered by insurance, what help or services would you be willing to pay for?

6. If you needed help understanding or help managing services, which services would you be willing to pay someone to manage for you or give you advice about?

7. How much would you be willing to pay for that advice and/or management? How much per month? How much per year? 
The responses were recorded in Microsoft Word and analyzed using the specialized cluster analysis software. The resulting concepts are shown in Exhibit 2.

\section{EXHIBIT 2}

Help coordinating bills

A sympathetic person to talk to

Transportation

Understanding and coordinating doctors' information

Housekeeping

Understanding and coordinating insurance information

Medical homecare

These concepts were then submitted to a DME survey generator, creating a survey arraying service attributes from the cluster analysis to include the Life Institute's coordinated care service, titled Care Support of America or CSA, a prepaid health package, and the Self. The resulting questionnaire is found in Exhibit 3. The concepts chosen as the reference frame came from the domain of concepts as the final pairs.

\section{EXHIBIT 3}

Instructions

Please estimate how different or "far apart" each of the following words or phrases are from each of the others. The more different, or further apart they seem to be, the larger the number you should write. To help you know what size number to write, remember:

Homecare and Help Coordinating Bills are 100 units apart.

If two words or phrases are not different at all, please write zero (0). If you have no idea, just leave the space blank.

$\underline{\text { Home Care and Help Coordinating Bills are } 100 \text { units apart }}$

Help Coordinating bills and A sympathetic person to talk to

Help Coordinating bills and Transportation 
Help Coordinating bills and Understanding/Coordinating Doctor's Information

Help Coordinating bills and Housekeeping

Help Coordinating bills and Understanding/Coordinating Insurance Information

Help Coordinating bills and Prepaid Help Package/CSA

Help Coordinating bills and Homecare

Help Coordinating bills and Yourself

$\underline{\text { Home Care and Help Coordinating Bills are } 100 \text { units apart }}$

A Sympathetic person to talk to and Transportation

A Sympathetic person to talk to and Understanding/Coordinating Doctor's

Information

A Sympathetic person to talk to and Housekeeping

A Sympathetic person to talk to and Understanding/Coordinating Insurance Information

A Sympathetic person to talk to and Prepaid Help Package/CSA

A Sympathetic person to talk to and Homecare

A Sympathetic person to talk to and Yourself

Transportation and Understanding/Coordinating Doctor's Information

$\underline{\text { Home Care and Help Coordinating Bills are } 100 \text { units apart }}$

Transportation and Housekeeping

Transportation and Understanding/Coordinating Insurance Information

Transportation and Prepaid Help Package/CSA

Transportation and Homecare

Transportation and Yourself 


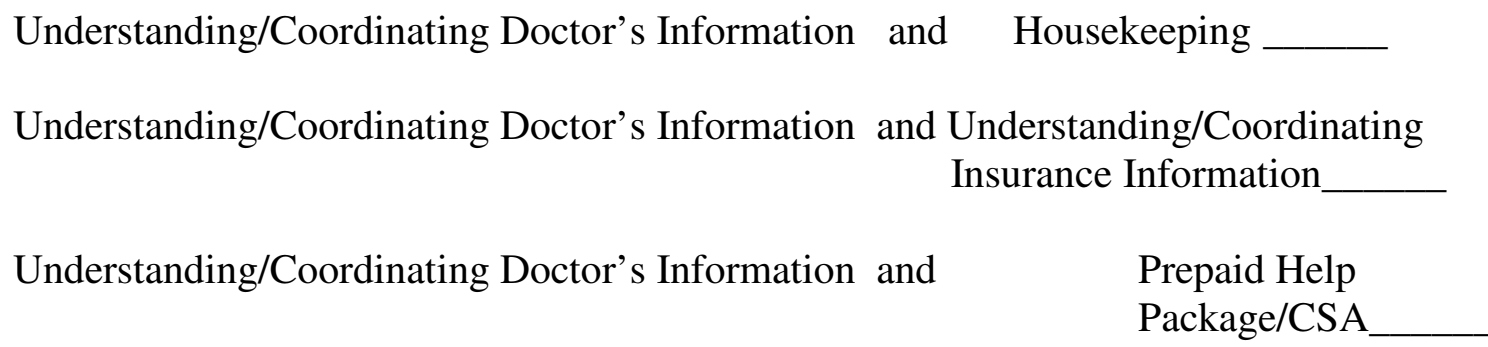

$\underline{\text { Home Care and Help Coordinating Bills are } 100 \text { units apart }}$

Understanding/Coordinating Doctor's Information and Homecare

Understanding/Coordinating Doctor's Information and Yourself

Housekeeping and Understanding/Coordinating Insurance Information

Housekeeping and Prepaid Help Package/CSA

Housekeeping and Homecare

Housekeeping and Yourself

Understanding/Coordinating Insurance Information and Prepaid Help Package/CSA

Understanding/Coordinating Insurance Information and Homecare $\underline{\text { Home Care and Help Coordinating Bills are } 100 \text { units apart }}$ Understanding/Coordinating Insurance Information and Yourself Prepaid Help Package/CSA and Homecare Prepaid Help Package/CSA and Yourself Homecare and Yourself

The distance questionnaire was administered to a convenience sample of 115 respondents. The respondents were selected using a convenience sample with the intention of performing demographic analysis to determine market representation (Hussein Abdulla ElOmari, 2007; Chang, 2006; Duguay, et al., 2003; Cropley, et al., 2002). Even so, the respondents were chosen from a close approximation of the potential market sought by the 
coordinated care services program. The distance questionnaire was administered to participants at the Family Business Resource Council as well as to graduate students in the Graduate Programs in Management at Sage Graduate School, specifically from the Health Services Administration, Public Administration, MBA, and Organizational Management programs. These respondents appeared to represent potential caregivers of parents and other relatives who would be in need of coordinated care services.

\section{Findings:}

The total number of useable responses was 113. The age of the respondents completing the distance questionnaire, ranged from 21 to 67 years with the mean being 35.14 years. The gender distribution was 64 females and 48 males. The annual income reported ranged from $\$ 8,000$ to $\$ 265,000$ with the mean being $\$ 59,890$. The number of respondents reporting they were, at present, caregivers was 9 and 103 were not. Most respondents reported living in suburban locations. Urban respondents numbered 26. Those reporting living in a rural area were 21. The average number of years of education completed was 16.82. The most frequently reported level of educational achievement was Bachelor's degree with the total number being 77. There were 16 Master's degree holders, 4 lawyers, and 1 M.D.

Similar care giver characteristics have been found in other health care research. Gupta and Pillai (2002) examined care givers to the elderly in the Dallas-Fort Worth, Texas area. Their findings show care giver characteristics of 30 years of age on average. Eighty percent had some college or more education. Fifty nine percent of care givers in the Gupta and Pillai sample were daughters or daughters-in-law of the elderly needing care.

\section{Findings: Dimensionality}


In consideration of Bigne, et al., analyzing the pattern of the conceptual space in which magnitude estimation based concepts can reside is critical to the analysis. Therefore, uncovering the number of dimensions in the space was the first step to undertake in the analysis. The dimensionality of the space is an extension of multidimensional scaling. Human cognition, in concept mapping analysis, exists in conceptual space in the same way that physicists conceive of and measure interstellar space. Cognitive space is curved in the same way that physicists observe interstellar space. There can be two types of space in multidimensional concept mapping methodology, as there are in physics; Euclidean, consisting of flat dimensions and Riemannian, consisting of curved dimensions. As a result, understanding the bending of the space around product attributes is essential. The movement across conceptual space is as different as plotting and traversing the distance from New York City to Los Angeles as compared to plotting and traversing the distance between Earth and Mars. The distance between New York City and Los Angeles can be plotted using a wall map, which is flat. The distance between Earth and Mars must be plotted considering the rotation of both planets and their movement around the sun creating curvature of the space between the two objects. In traversing the distance between New York City and Los Angeles the traveler does not have to account for the movement of New York City or Los Angeles and/or his/her own movement.

The number of Euclidean or plane space dimensions uncovered was seven and the number of Reimannian or curved space dimensions was two. This finding is particularly noteworthy because the meaning of the space in which the product attributes or concepts is found significantly affects the interpretation of the distance between and, ultimately, among the product attributes or, in this case, the coordinated care services attributes. Moving concepts in conceptual space is like moving across outer space with NASA space probes. Simply put, when 
interpreting the distances between and among product attributes or, in this case, coordinated care services attributes, the distances that must be addressed with persuasive messages cannot be interpreted as linear. Figure 1 is the graphic representation of the resulting map based on the distance data.

While the analytic software is able to represent the product attributes or concepts in three dimensional space, the map displayed here is the two dimensional representation. Thus, the distances represented in the map cannot clearly demonstrate the curvature. Nevertheless, the space is curved and, therefore, must be interpreted numerically.

The most meaningful way to interpret a multidimensional space in DME concept mapping is to represent the data between pairs in a rank ordering based on distance and space curvature. Exhibit 4 provides the rank ordering from the closest pair to the most distant pair found in the analysis.

\section{EXHIBIT 4}

Message

1

2

3

4

\section{Concepts}

Housekeeping

Understanding and Coordinating Insurance Information

A Sympathetic Person to Talk to

Housekeeping

Understanding and Coordinating Insurance Information

Understanding and Coordinating Doctor's Information Housekeeping

Understanding and Coordinating Insurance Information

Understanding and Coordinating Doctor's Information Housekeeping

A Sympathetic Person to Talk to

Transportation

Housekeeping

Understanding and Coordinating Insurance Information 
A Sympathetic Person to Talk to

Understanding and Coordinating Doctor's Information

Housekeeping

Understanding and Coordinating Insurance Information

A Sympathetic Person to Talk to

Housekeeping

Understanding and Coordinating Insurance Information

Prepaid Help Package

8

Transportation

Understanding and Coordinating Doctor's Information

Housekeeping

Understanding and Coordinating Insurance Information

9

Transportation

Housekeeping

Understanding and Coordinating Insurance Information

10

A Sympathetic Person to Talk to

Understanding and Coordinating Doctor's Information

Housekeeping

Given the curvature of the conceptual space for the coordinated care services, adding a third concept became important to the development of the persuasive messages. Using the three concept/product attribute combination changed the concept combinations. The rank ordering of the three concepts most appropriate for the curvature of the space is shown in Exhibit 5.

\section{EXHIBIT 5}

Message Concepts
Housekeeping
Understanding and Coordinating Insurance Information
Prepaid Help Package
Transportation
Housekeeping
Understanding and Coordinating Insurance Information
Prepaid Help Package


Housekeeping


Understanding and Coordinating Insurance Information

4

5

6

7

8

9

10
A Sympathetic Person to Talk to

Transportation

Housekeeping

Understanding and Coordinating Insurance Information

Transportation

Housekeeping

Understanding and Coordinating Insurance Information

A Sympathetic Person to Talk to

Housekeeping

Understanding and Coordinating Insurance Information

Prepaid Help Package

Transportation

Understanding and Coordinating Insurance Information

Prepaid Help Package

A Sympathetic Person to Talk to

Transportation

Housekeeping

Prepaid Help Package

A Sympathetic Person to Talk to

Housekeeping

Understanding and Coordinating Insurance Information

A Sympathetic Person to Talk to

Transportation

Understanding and Coordinating Insurance Information Prepaid Help Package

\section{Resulting Persuasive Messages:}

Based on the combinations, relative distances, and the interpretation of the conceptual space in which they exist, a series of persuasive messages, i.e., marketing messages, was generated. At this point creativity was combined with the multidimensional concept mapping research. The resulting messages are found in Exhibit 6. As can be seen from the messages generated, a combination of the most important product attributes or, concepts, added to a 
marketing context for coordinated care services, has been produced. In addition, the creativity portion of marketing messages for coordinated care services was associated with appropriate message delivery media. Message 1 was determined to be most effective and, therefore, should be delivered using radio. Messages 2-9 were determined to be most effectively delivered by print ads and webpage copy. Edell and Keller studied coordinated marketing campaigns and discovered a coordinated campaign can be more efficient than using one medium alone (Edell \& Keller, 1989). Stafford and Day note in their research of services that radio ads "generated higher levels of patronage intention than print ads" (Stafford \& Day, 1995).

Given the complexity of the space and the three concept combinations, radio media were thought to be the strongest delivery mechanism (Baker \& Lutz, 2000). The remaining messages were considered to be supportive. The combination of media was based not only on the map of product attributes but also on the budget of the non-profit organization.

\section{EXHIBIT 6}

\section{INTRODUCING CARE SUPPORT OF AMERICA!}

CSA is a help oriented organization that provides a prepaid care package to assist family members or loved ones with chronic or serious illnesses. A trained professional is assigned to an individual's case to help the individual in financial matters, such as coordinating insurance information; help in practical matters such as housekeeping; and help in emotional matters by having a sympathetic ear to listen to concerns about the many areas of serious illness.

2. Care Support of America is here to Help!

Help when serious illness strikes you, your family or someone you love!

3. CSA can help!

CSA is prepaid insurance for coordinating insurance information for those who are seriously ill or the families of those who are seriously ill.

Help with Housekeeping! 
Help by providing a sympathetic ear!

4. Is Someone in Your Family Sick? CSA can help!

CSA can help with insurance benefit coordination!

CSA can help keep the house clean and clutter free during the illness!

CSA is your prepaid help insurance package!

Available when illness strikes! CSA is a prepaid insurance package for you!

5. Someone ILL in your family? Call a CARE

SUPPORT of AMERICA Representative

FOR

The help you need with insurance coverage!

Help Keeping the House Clean while the family member or you are ill!

All these services are offered through the CSA prepaid insurance program!

6. Help with Insurance coverage! Housekeeping! Helping is what CSA does through its prepaid insurance package. Let CSA listen sympathetically to you and help when illness touches you, your family, or people you love.

7. CSA, your prepaid help insurance package, can assist in supporting you and your family if serious illness strikes. When serious illness strikes your ability to keep the household clean and orderly and pay bills on time will be reduced. CSA can coordinate service to help with these things. CSA will also be around to listen sympathetically as you, your family, or a loved one work through the illness.

8. When illness strikes CSA can help! CSA is a prepaid insurance package that can assist with household chores and cleaning and getting bills paid on time. Most importantly, CSA is there to listen sympathetically when you most need it!

9. Need someone to listen to you when you are seriously ill? Need someone to listen sympathetically if a family member or close friend is ill? Call Care Support of America, the prepaid help package that creates the services you need at such a time. CSA will listen sympathetically! CSA will assist with housekeeping chores! CSA will help get bills paid on time!

The delivery of messages concerning CSA and the potential customer is equivalent to NASA space probes attempting to intersect an asteroid. In order to do so, the location in curved interstellar space must be balanced with the size of the asteroid and the power of the NASA probe.

\section{Discussion:}


Neural network analysis combined with DME software analysis is a significant adjunct to sound marketing. Since the DME concept mapping begins with neural network analysis of potential caregivers, it provides natural categorization of product attributes generated by potential caregivers rather than by researchers. Neural network analysis provided by the software allows researchers to understand how potential caregivers are thinking or, conversely, not thinking about coordinated care service.

The attribute clusters when measured with DME give the researchers further information. As such, marketing and persuasive messages can be crafted in a more complete way. This kind of information is particularly important, not only for the generation of persuasive messages with likely greater impact, but also because a predictable amount of market share is generated by those messages. Providers may then be in a more favorable position to advertise, promote, and otherwise persuade potential market members to accept and buy their products and/or services.

The amount of management control available to care providers can be increased because providers can understand the point at which they begin in the market and, with follow-on analysis using DME concept mapping, can judge how far they need to go. As with planning any "journey", understanding distance is only part of the trip. The terrain and conditions of travel must also be understood.

Although sampling error may be a consideration in the coordinated care services research presented here, the descriptive data indicate that the respondents are, in profile, like typical caregivers in a coordinated services context. It is likely, therefore, that the kind of purchasers of such services of coordinated care are, in fact, represented among the respondents reported here (Pinquart \& Sorensen, 2006). The respondents have among them those persons not currently caregivers. Such market respondents are the kinds of adults who unexpectedly find 
themselves in such circumstances. These respondents are the potential market for who coordinated care services are, in large measure, intended.

Given the likely representative sample of respondents, the distance between the CSA service and the average self point as uncovered by the DME analysis is the best indication of market share. The ability to predict market share at the beginning of a persuasive message campaign facilitates mid-course alterations to a marketing campaign if necessary. Since the

DME based concept mapping provides considerable information from the beginning and can be used for subsequent market examination, no mid-course corrections may be necessary. In either case, the DME concept mapping based messages allow steering across a complex marketing topography.

Based on the results of DME concept mapping research in other marketing contexts, the CSA messages have a high probability of success. Naturally, the executive management of the Life Institute and CSA must apply the messages and the delivery mechanisms as provided by the multidimensional analysis and the creativity of the market researchers. With these elements present CSA can measure the results of its persuasive messages against the market share predicted by the data because of the measurement of distance between the concepts of self and the CSA service. The map of DME based concepts provides CSA executive management with a plan to navigate the market terrain uncovered here.

\section{Conclusion: Theoretical and Practical Applications}

\section{Theory Building}

The results from the concept mapping presented here have utility for health care marketing theory building and for practical health care marketing applications. From the theory building perspective, concept mapping using the combination of qualitative and quantitative 
methods, creates “power and benefits", according to Freeman and Jessup (2004). Adding the DME measurement creates the ability to uncover the number of dimensions in the conceptual map. The inclusion of the measurement will improve the clarity and construction of the marketing message and add vigor to a resulting marketing campaign.

The dimensions of the DME concept map created here point to the complexity of the thinking space of potential market customers. Those dimensions must be understood as the "hurdles" which must be overcome to make a persuasive message. In other words, creating a message must be combined with effective persuasive delivery. The curvatures of the mind in which the ideas or concepts of coordinated care exist must be considered.

DME concept mapping creates clarity of concepts in marketing research. The conceptual map presented in Exhibit 1, details individual concepts and in addition to the domain or thinking space in which they exist. The domain revealed here is one that can be objectively verified because of the use of DME. Additionally, that domain can be treated as the beginning of a theoretical understanding of how the cognition about coordinated care concepts are understood by potential care givers. The DME scaling allows more concepts to be included later. As the market research application of concept mapping expands, the number of concepts discovered can be added. The ability to find contiguous concepts and uncover more dimensions will lead to a greater understanding of how cognition about the service attributes relate to one another.

While the map itself is not the theory, the map provides "the framework" for theory, according to Trochim (2003). Theory requires the use of independent and dependent variables. In the case of the DME concept map, the dependent variable is the coordinated care service and the independent variable is the message derived from interpreting the map. Delivering the marketing message, then tracking the resulting market changes, will result in designating the map location 
of the service relative to the self point. Moreover, the ability to find the combination of product attributes to use in the context of the marketing message increases the ability of the message to move those attributes across the domain's or the thinking space dimensions. The mapping of dimensions can lead to a positive marketing perception for the target customers.

Theory building also requires reproducibility of results. The DME concept mapping approach creates such reproducibility. The scale of distance used in the coordinated care research here can be applied in other coordinated care marketing research. The scale of distance using the reference pair is the key ingredient. Use of the same reference pair can also be applied in other health care services marketing.

Theory building can then proceed from the measurement of distance among concepts. The resulting map can be added to the one here to increase the theoretical framework described by Trochim (2003).

\section{$\underline{\text { Practical Applications }}$}

The theoretical implications inform the practical implications. The clarity of concepts and the identification of dimensions or, thinking space, means that marketers have more information. More information combined with creativity will likely yield more informational and appealing marketing messages for potential customers. Thus increasing the health care serivce's potential market share as well as provide an appealing service to customers.

Some researchers have found that one third of advertising dollars are wasted on ill conceived messages that miss the target audience. In health care marketing such waste is no longer allowable in the face of continued health care reimbursement reductions. Every dollar spent must be spent wisely in a well crafted and thoroughly considered process. The days of spending money on marketing campaigns not fully informed are over. Group practices and 
major medical facilities need to continue to take a very strategic approach to health care marketing. Consequently, the use of concept mapping with DME measurement will yield informed results in order to make sure that marketing messages works in cost conservative environment. The result will be a greater share of the market demographic for fewer marketing dollars.

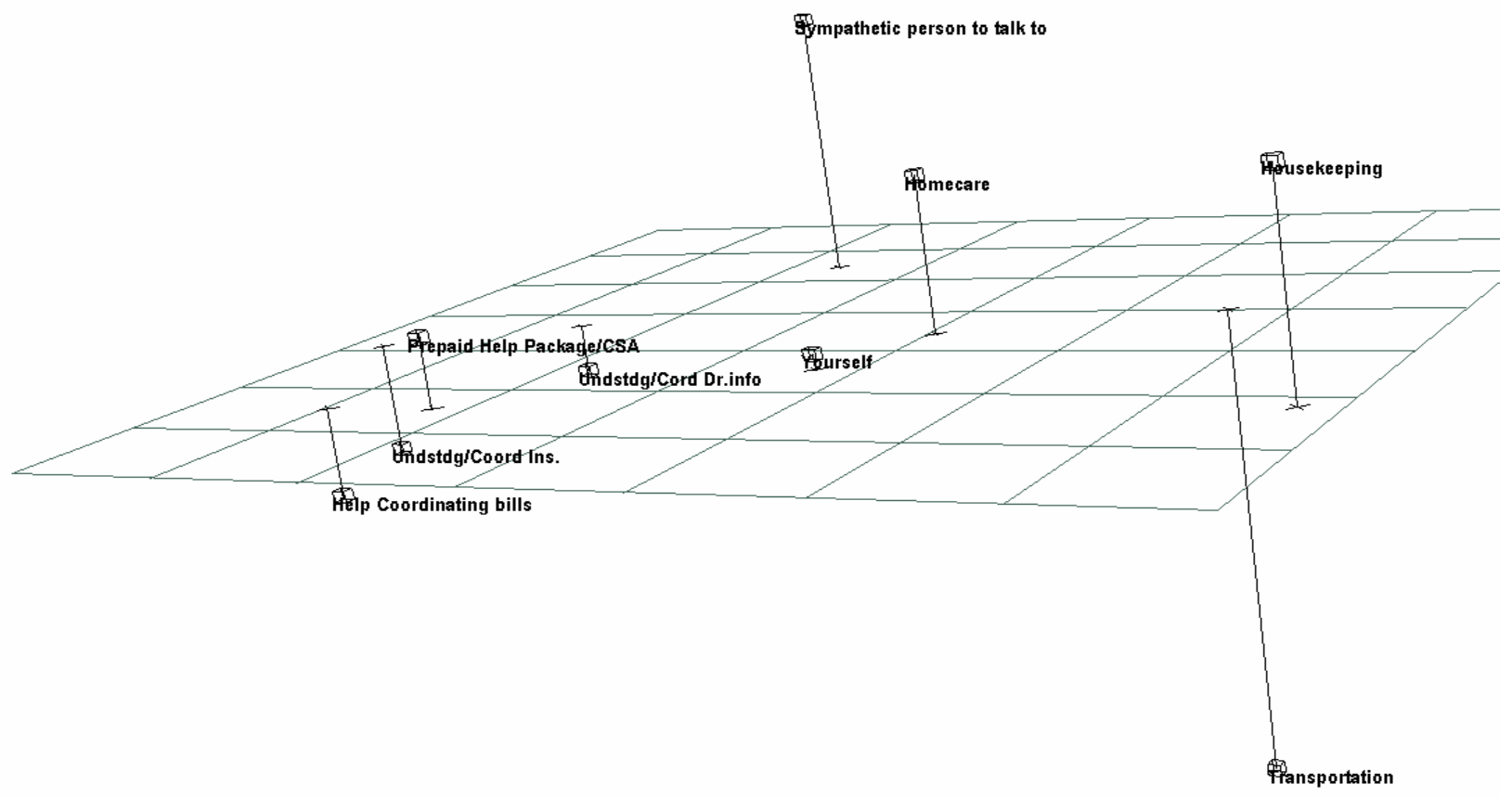

Figure 1. The graphic representation of the resulting map based on the distance data 
Baker, W.E. \& Lutz, R.J. (2000). An empirical test of an updated relevant-accessibility model of advertising effectiveness. Journal of Advertising, 29(1), 1-14.

Berkowitz, E.N. (1996). Essentials of health care marketing. Maryland: Aspen Publishers, Inc. Bigne, J.E.; Aldas-Manzano, J.; Kuster, I.; Vila, N.(2002). The concept mapping approach in marketing: an application in the travel agencies, Qualitative Marketing Research, 5(2), 87-100. Born, M. (1965). Einstein's theory of relativity. New York: Dover.

Chang, J. \& Hsieh, A. (2006). Leisure motives of eating out in night markets. Journal of Business Research, 59(12), 59-71.

Cropley, L; Mitchell, F.; Anderson, P.B. (2002). Report on a formative evaluation conducted for the youth against tobacco counter marketing campaign. American Journal of Health Studies, 17(4), 181-186.

Duguay, F.; Katsanis, L.P.; Thakor, M.V. (2003). The identification of factors linked to potential acceptance of transgenic biopharmaceuticals: an exploratory study. Health Marketing Quaterly, $21(1,2), 65$.

Eadie, T.L. \& Doyle, P.C. (2002). Direct magnitude estimation and interval scaling of naturalness and severity in tracheoesophageal (TE) speakers. Journalof Speech, Language, and Hearing Research, 45, 1088-1096.

Edell, J.A. \& Keller, K.L. (1989). The information processing of coordinated media campaigns. Journal of Marketing Research, 26(2), 149-163.

Gupta, R. \& Pillai, V.K. (2002). Elder care giving in south asian families: implications for social service. Journal of Comparative Family Studies, 33(4. 565-576. 
Freeman, L.A. \& Jessup, L.M. (2004). The power and benefits of concept mapping: measuring use, usefulness, ease of use, and satisfaction. International Journal of Science Education, 26(2). 151-169.

Hussein Abdulla El-Omari, H.A. (2007). Emiratis' dmographics and their reaction to TV commercial breaks: the case of the emirate of sharjah (UAE). The Business Review, Cambridge. Hollywood: Dec 2007. 8( 2). 222-231.

Ouwens, M., Wollersheim, H., Hermens, R., Hulscher, M., \& Grol, R. (2005). Integrated care programmes for chronically ill patients: A review of systematic reviews. International Journal for Quality in Health Care, $17,141-145$.

Pinquart, M. \& Sorensen, S. (2006). Gender differences in caregiver stressors, social resources, and health: An updated meta-analysis. The Journals of Gerontology: Series B: Psychological sciences and social sciences, 61B, 33-45.

Rantz, M.J., Marek, K.D., \& Zwygart-Stauffacher, M. (2000). The future of long-term care for the chronically ill. Nursing Administration Quarterly, $15,51-57$.

Shewchuk, R. \& O’Connor, S.J., (2002). Using cognitive concept mapping to understand what health care means to the elderly: an illustrative approach for planning and marketing. Health Marketing Quarterly, 20(2), 69-88.

Somers, M.J. (2001). Thinking differently: assessing nonlinearities in the relationship between work attitudes and job performance using Bayesian neural network. Journal of Occupational \& Organizational Psychology, 74(1), 47-61. 
Song, M. \& Zhao, Y. (2004). A neural network analysis for predicting manufacturers's perceived cooperation with distributors in the new product development process. Journal of Business-toBusiness Marketing, 11(3), 53-78.

Stafford, M.R. \& Day, E. (1995). Retail services advertising: the effects of appeal, medium, and service. Journal of Advertising, 24(1), 57-71.

Stanton, J.L. \& Lowenhar, J.A., (1977). Perceptual mapping of consumer products and television shows. Journal of Advertising, Spring 77, 6(2), 16-22.

Starfield B. (1998). Primary care: Balancing health needs, services, and technology. New York: Oxford University Press.

Stille, C.J., Jerant, A., Bell, D., Meltzer, D., \& Elmore, J.G. (2005). Coordinating care across disease, settings, and clinicians: A key role for the generalist in practice. Annals of Internal Medicine, 142, 700-708.

Trochim, W.M., Cabrera, D.A.; Milstein, B.; Glallagher, R.S.; Leischow, S.J. (2006), Practical challenges of systems thinking and modeling in public health, American Journal of Public Health, 96(3), 538-547.

Trochim, W.M.., Stillman, F.A., Clark, P.I., \& Schmitt, C.L. (2003). Development of a model of the tobacco industry's interference with tobacco control programmes. Tobacco Control, 12, 140-147.

Whitehill, T.L., Lee, A.S.Y, \& Chun, J.C. (2002). Direct magnitude estimation and interval scaling of hypernasality. Journal of Speech, Language, and Hearing Research, $45,80-88$.

Woelfel, J. (1993). Artificial Neural Networks for Cluster Analysis. Paper presented at the American Marketing Association Attitude Research Conference, Phoenix, AZ, Jan, 1993. 
Non-profit Health Care Services Marketing Page 28 of 23

Woelfel, J. \& Fink, E.L. (1980). The measurement of communication processes: Galileo theory and method. New York: Academic Press. 